\title{
Giving the public a perspective into Unmanned Aircraft Systems' operations
}

\author{
Lynne Martin \\ NASA Ames \\ Moffett Field, USA \\ lynne.martin@nasa.gov \\ Cesar Ramirez \\ ASRC Research \& Technology Solutions \\ at NASA Ames \\ Moffett Field, USA \\ cesar.g.ramirez@nasa.gov
}

\author{
Jeffrey Homola \\ NASA Ames \\ Moffett Field, USA \\ jeffrey.r.homola@nasa.gov
}

\author{
Faisal Omar \\ San Jose State University \\ at NASA Ames \\ Moffett Field, USA \\ faisal.g.omar@nasa.gov
}

\author{
Kimberly Jobe \\ San Jose State University \\ at NASA Ames \\ Moffett Field, USA \\ kimberly.k.jobe@nasa.gov
}

\begin{abstract}
NASA is currently engaged in research to safely enable large-scale commercial applications of small Unmanned Aircraft Systems (UAS) in low altitude airspace. This research effort, referred to as UAS Traffic Management (UTM), encompasses the concepts and technologies needed to accommodate the projected demand of UAS operating in the national airspace. One aspect related to the successful implementation of UTM in the future is public acceptance. UTM transparency will heavily influence this acceptance, and a public portal will provide much of that transparency through ease of access to information about the operations - mainly why and where such operations are taking place. Related concerns to the public are individual privacy, security, and accountability of the operators. Providing the aforementioned information about operations can mitigate these concerns, but a balance will have to be achieved between the need for transparency from the public and the privacy of the operators. The proper balance and the needs of the various UTM stakeholders with regard to information access is being explored through the development and testing of a public portal alongside NASA's development and flight testing of the UTM system. Additionally, various approaches to the display of information and user interfaces were surveyed through the development of different instantiations of a public portal by multiple UTM industry partners across different test sites.
\end{abstract}

Keywords-UTM, UAS, public portal, automation

\section{INTRODUCTION}

The FAA estimates the number of daily UAS operations could potentially be millions of flights [1], since they project that the combined hobbyist and commercial UAS fleet is likely to reach over three million by 2021. NASA is currently researching how to safely enable large-scale commercial applications of small (below 55 pounds) unmanned aircraft systems (UAS) in low altitude U.S. airspace. This research effort, referred to as UAS Traffic Management (UTM), encompasses the concepts and technologies needed to accommodate the projected demand of UAS operating in the national airspace. Initially, most of these small UAS flights will take place in uncontrolled, Class G, airspace that is below 400 feet above ground level. Air Traffic Controllers are not required to provide separation services in Class G airspace, and manned aircraft follow operational procedures to fly safely within this airspace. UTM is intended to provide UAS with the same access as manned aircraft, using a similar means of cooperative traffic management [1] but with a greater degree of automation. That is, UAS operators will need to follow principles of operation laid out by the FAA that include cooperative negotiation with other users to stay well-clear of each other.

One aspect related to the successful implementation of UTM in the future is public acceptance. How will the public react to a large volume of very low altitude airborne traffic? Studies have shown (e.g.,[2]) that the public is concerned about individual privacy and security as well as safety and reliability 
of the unmanned vehicles themselves, and accountability of operators. However, currently they do not have a means to inform themselves about UAS activity [3]. Envisioned in the UTM concept is the ability for members of the general public to access information about the UTM environment for awareness and understanding of UAS activity via an accessible platform referred to as a public portal. Other user groups will also want access to UTM information to support planning, safety, and response at various levels and scope. One proposal is to make information about UAS operations available to the general public as an additional service of the UTM ecosystem. Data would be provided through this route to populate a portal that, for example, might be a website or application, potentially with a map as a base layer. UAS, and some level of detail about their mission, could then be shown through this application with one intention being to assuage public concern. The FAA already provides a list of flight restrictions to UAS operators [4] and it is envisaged a public portal could complement this.

The "general public" are a heterogeneous group and, in the future environment, access to UTM information will likely be desired by different user groups for different reasons. In addition to hobbyists and "the person next door," user groups will include government offices and municipalities, whose responsibilities include relationships with commercial and safety related UAS use, and public safety teams - law enforcement, fire protection, and other first responders - whose missions may require knowledge of UAS activity.

To understand the perspectives and needs of these potential public users and the concerns of UAS operators, the research project reported below is reaching out to these different user segments. This research has two phases. First, focus groups, each including at least one person from each of the general public and municipality, or first responder user segments, were asked to explore the opinions and rationales of these different user-groups. Their discussions are summarized below. A second phase, currently underway and not reported here, will focus on the user opinions of the functionality and access provided by a prototype public portal design.

While it is acknowledged that showing the public information about UAS flight activity could increase acceptance, in counter-arguments, concerns have been raised by commercial operators over operational privacy, mission and data security, and public objections that may curtail their operations. Thus, it seems likely that a balance will have to be achieved between the desire for information from the public and the need for confidentiality for the operators. The proper balance and the needs of the various UTM stakeholders, with regard to information access, is being explored through the development and testing of a public portal as part of NASA's UTM development and flight demonstrations (see [5], [6] for descriptions of previous flight tests). To ensure that a breadth of opinion is gathered, a number of industry partners participating in UTM flight testing will also create example public information portals and run studies to gather local public opinion.
The industry partners, participating in the UTM flight tests, have well-established applications that they use in support of their UAS testing and mission performance activities. However, as the public will require different levels of access to UTM data, a requirement was to modify the existing applications such that the interface was tailored for use by the general public and other user segments (e.g., public safety entities and municipalities). Four of these partners are also developing public portals from their original USS (UAS Service Supplier) designs, ensuring a variety of portal examples. The partners were asked to demonstrate their prototype public portals to a small group of user-participants and ask them to use it to complete a number of candidate tasks. The tasks included navigating using the portal displays to find vehicles and then to find information about that vehicle, such as type of operation.

The aim of the public portal development work is to create a browser and/or app-based tool for an anonymous member of the general public to access appropriate UTM information. In the future environment, access to UTM information will likely be desired by different user groups for different reasons. To understand the perspectives and needs of these potential users, this study requires a level of outreach to different user segments. The development of a public portal prototype and exploration of the needs and concerns of those who want to use such an application and those who will be supplying information were, and will be, addressed through public participation. Focus group discussions, in which different stakeholder groups were invited to engage in collaborative discussions of a series of questions are presented below. Discussion topics included detailing participants' concerns, discussing desired restrictions on UAS activity, and functions that a public portal should serve.

\section{A. Current tools displaying UTM information}

In addition to an client interface that enables flight geometries to be submitted to the UTM system, which is a little more rudimentary than those developed by industry partners, the UTM laboratory at NASA Ames Research Center has developed a number of purpose-built in-house tools that were constructed to assist with situation awareness, test support, UTM data collection and data management. One of these is the Situation Display (SD) tool. It has a web interface that links to a data collection repository and streaming service. The tool draws data from the UTM system, in particular the UDC (USS Data Collector), and creates a visualization of those data which the user can then filter and sort in real time, and edit, if necessary, to support data collection. The SD is written in Javascript (ES6+) and will run on any browser, although Chrome has been most often used. The server component, BatchServer, is a Nodejs application, which is OS independent. It communicates directly to some UTM services, but also subscribes to data via a data relay to populate the tool. BatchServer uses a Feathersjs framework, which allows flexibility and interchangeability of the backend database. $\mathrm{NeDb}$ is being used for small "session" data sets, such as the one which will be used as a scenario for the phase 2 study. 


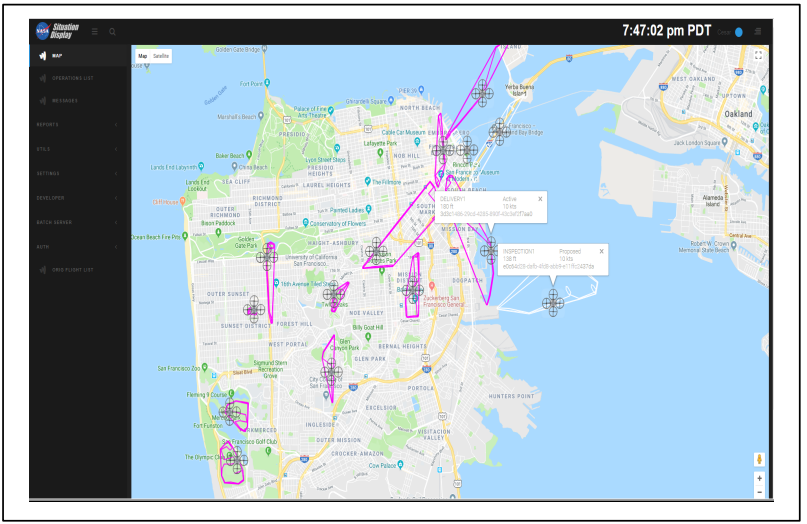

Fig. 1. Situation Display map display example, with operation volumes and vehicle positions

The Situation Display represents data in two ways - either on a map display (Figure 1) or in tabular format (Figure 2). The map display, supplied by Google Earth [7], shows a satellite or road layout view on which operations and aircraft telemetry that are known to the UTM system are represented. The color of the operations indicate the state of that operation. Aircraft shown on the map have optional data blocks that contain limited flight information, mainly about flight parameters. The map view opens around your "home" location but can be dragged to the area of interest. There are a number of tables to complement this map view, each of which focuses on a different set of information, that can be accessed from a menu in a left bar. The most commonly used during data collection are the registration, operations, and messages tables. Registration tables show the certification details for the currently active and proposed flights, and message tables show the UTM messages that are flowing through the UTM system at a rate of one Hertz. Operations tables contains details about the nature of the flight, its status and the USS, while a drop-down panel lists the operators, flight parameters and vehicle details. Each table is equipped with a scrollbar, and can be filtered and sorted on any of its columns to facilitate data management. Each page shows approximately 40 flights when displayed on a 26-inch monitor.

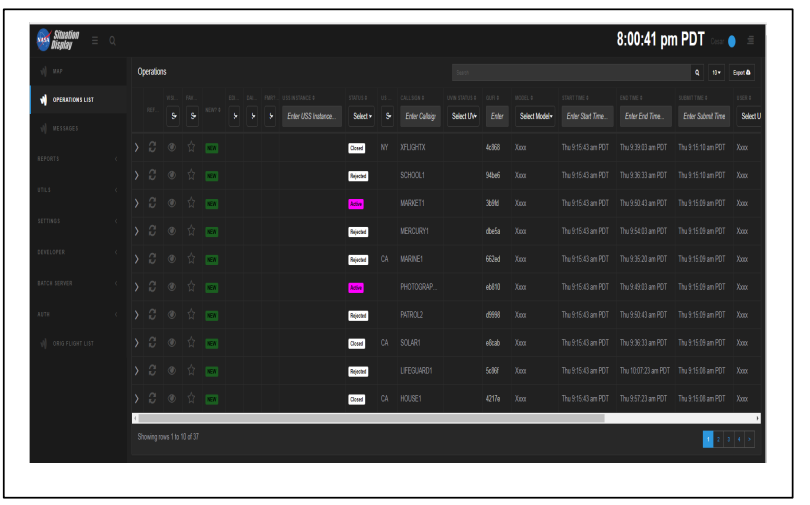

Fig. 2. Situation Display tabular display example, showing the operations list with status and operations' times

\section{MEthodS}

\section{A. Participants}

Participants were invited from the domains of industry, government/ municipality, public safety, and the general population. It was intended to include at least one person from the following mutually exclusive groups in the final set of participants:

- General Public: Any adult member of the public.

- Public Safety: Individuals from law enforcement, fire protection, or first responders.

- Government/Municipality: Individuals from state, local, or city governments with responsibilities that may have relationships with commercial and safety related UAS use.

- Industry: A representative of a company that intends to be a service provider in the future UTM environment.

In total, 31 participants took part in the discussions. Twenty eight participants attended one of four focus groups, and three people participated as individuals in one-on-one interviews, either by telephone or in person. The work-roles that participants held varied widely, see Table I for a list of the types of occupations of the participants. The focus groups had a good number of participants attending from government, general public and first responder/ safety fields but, as shown in Table I, industry participants were under-represented.

TABLE I. PARTICIPANTS' OCCUPATIONAL FIELD

\begin{tabular}{|l|c|l|c|}
\hline $\begin{array}{l}\text { Occupation } \\
\text { type }\end{array}$ & $\begin{array}{l}\text { Number of } \\
\text { partici- } \\
\text { pants }\end{array}$ & $\begin{array}{l}\text { Occupation } \\
\text { type }\end{array}$ & $\begin{array}{l}\text { Number of } \\
\text { partici- } \\
\text { pants }\end{array}$ \\
\hline $\begin{array}{l}\text { City } \\
\text { government }\end{array}$ & 3 & $\begin{array}{l}\text { Airport } \\
\text { operations }\end{array}$ & 3 \\
\hline $\begin{array}{l}\text { Law } \\
\text { enforcement }\end{array}$ & 5 & $\begin{array}{l}\text { Utility } \\
\text { services }\end{array}$ & 3 \\
\hline Park rangers & 2 & Education & 2 \\
\hline $\begin{array}{l}\text { Search \& } \\
\text { rescue }\end{array}$ & 3 & $\begin{array}{l}\text { Private } \\
\text { citizens }\end{array}$ & 7 \\
\hline Fire service & 2 & Non profit & 1 \\
\hline
\end{tabular}

\section{B. Method}

After a short introduction to the UTM concept, participants were invited to a demonstration of the prototype UTM system where they could ask questions, and were briefly introduced to the SD tool, which shares some features with the proposed public portal tool. These discussions lasted approximately an hour. Following this, the group moved into discussion about their preferences for an accessible UTM tool. A researcher guided the discussion to cover four topics (and two subtopics) of interest: 
- the information public users would like to see on a tool,

- the functions users would like a tool to have,

- ways participants would like to filter or restrict information,

- participants' concerns and how they could be addressed

Examples of the way these topics were raised as questions are depicted in Table II.

The focus group discussions were structured such that the pre-formulated question set could be addressed. Although the researcher guided each group to discuss all four topics within each meeting, there was no set format for how questions were introduced, allowing for flexibility in discussions and topics to emerge opportunistically.

TABLE II. PROMPT QUESTIONS FOR FOCUS GROUPS

\begin{tabular}{|c|c|}
\hline Topic & Example question \\
\hline 1.Function & $\begin{array}{l}\text { What function or purpose do } \\
\text { you think a public portal } \\
\text { should serve? }\end{array}$ \\
\hline $\begin{array}{l}\text { 2.Information } \\
\text { desired }\end{array}$ & $\begin{array}{l}\text { What information do you } \\
\text { want to see with regard to } \\
\text { UTM and UAS operations } \\
\text { taking place in your local } \\
\text { area/ area of responsibility? }\end{array}$ \\
\hline $\begin{array}{l}\text { 3.Filtering } \\
\text { information }\end{array}$ & $\begin{array}{l}\text { What are some types of } \\
\text { information you might not } \\
\text { want to see but want access } \\
\text { to if needed? }\end{array}$ \\
\hline $\begin{array}{l}\text { 3b.Restricting } \\
\text { information }\end{array}$ & $\begin{array}{l}\text { What information do you } \\
\text { want to restrict availability to } \\
\text { regarding your UAS } \\
\text { operations? }\end{array}$ \\
\hline 4.Concerns & $\begin{array}{l}\text { What concerns, if any, do } \\
\text { you have about UAS } \\
\text { operations taking place near } \\
\text { your residence or area of } \\
\text { responsibility or any given } \\
\text { location you may be? Do } \\
\text { those concerns change by } \\
\text { location? }\end{array}$ \\
\hline $\begin{array}{l}\text { 4b.Solutions to } \\
\text { concerns }\end{array}$ & $\begin{array}{l}\text { Are there features that you } \\
\text { feel should be required for a } \\
\text { public portal to have that } \\
\text { address your concerns? }\end{array}$ \\
\hline
\end{tabular}

The focus groups captured approximately five and a half hours of discussion from potential general public users and around two hours of discussion from first responders. Three of the four focus group discussions and two of the interviews were recorded. Detailed notes were taken during the fourth focus group discussion and the third interview. Audio recordings were transcribed into an edited format, where pauses and crutch words were omitted, and the transcriber focused on understanding the content of the audio rather than word to word attention. This reduced clutter in the transcripts and focused on the sense of the discussion. Transcripts were analyzed using thematic coding analysis [8] - each transcript was divided into small segments of meaningful prose and then were coded, using the six topics listed in Table II as the initial set of categories. A summary of the points that were made about public access to UTM information are discussed below.

\section{DESCRIPTION OF DISCUSSIONS AND CONCERNS}

Participants in the focus group viewed the proposal of a public portal favorably, saying they could think of many uses for a UTM portal, ranging from general interest, to seeing what UAS activity there is in their area, to seeing how much use their competitors are making of UAS, to finding areas that are not under surveillance, and, for first responders, for UAS operations' decision making. In total, 353 comments relevant to UTM were identified in the focus group discussions (Table III). Fifty one percent of the comments focused on information or functions the participants would like to see in a publicly available tool. Most comments were relevant to a tool that is would be accessible by the public, but $16 \%$ focused on topics that only first responders/ priority users would be concerned with. Participants also shared a number of concerns (74 comments). A selection of the most relevant topics and comments are discussed below.

TABLE III. TALLY OF FOCUS GROUP NUMBER OF COMMENTS

\begin{tabular}{|l|c|c|c|}
\hline $\begin{array}{l}\text { Prompt } \\
\text { topic }\end{array}$ & $\begin{array}{l}\text { Public } \\
\text { users \# } \\
\text { comments }\end{array}$ & $\begin{array}{l}\text { First } \\
\text { responders \# } \\
\text { comments }\end{array}$ & $\begin{array}{l}\text { Total } \\
\text { comments }\end{array}$ \\
\hline Functions & 73 & 14 & 87 \\
\hline $\begin{array}{l}\text { Information } \\
\text { desired }\end{array}$ & 80 & 11 & 91 \\
\hline $\begin{array}{l}\text { Filtering of } \\
\text { information }\end{array}$ & 14 & 2 & 16 \\
\hline $\begin{array}{l}\text { Restricting } \\
\text { information }\end{array}$ & 8 & 1 & 9 \\
\hline Concerns & 61 & 12 & 73 \\
\hline $\begin{array}{l}\text { Solutions } \\
\text { to concerns }\end{array}$ & 7 & 0 & 7 \\
\hline $\begin{array}{l}\text { Current } \\
\text { airspace } \\
\text { usage }\end{array}$ & 35 & 0 & 17 \\
\hline Concept & 12 & 57 & 347 \\
\hline Total & 290 & & \\
\hline
\end{tabular}

Participants listed 25 items of information about a UAS operation that they would like reported through a public portal. The items range from "what-where" facts, such as the location of the operation, to a statement of the uses that data collected by the vehicle could be put to. Of these items, ten are already presented in the SD tool described above, for example, the make and model of the vehicle. In the development of the public portal tool prototype four items are being added - a unique 
callsign that replaces the unique but non-user-friendly globally unique flight identifier (GUFI); more specific tabularized information about the location of the operation; and a listing of the mission and details about the mission. The presence of surveillance equipment was not specifically added, but the vehicle payload was, and for those operations that would be taking video footage, the payload is listed as a camera. In a second thread of discussion, participants additionally listed 20 features or functions they would like a portal to have, for example, an interactive map and a searchable table. Eight of these features are available through the UTM system to the SD in some way, although not all are implemented exactly as participants described them. The functionality of some of these features was increased for the public portal prototype, e.g., enabling a number of display elements to be hidden in addition to the data block.

Participants noted seven properties that they would like a public portal tool to have. They suggested that a tool would need to be easy to use, quick to respond, be portable or mobile (an app), represent one "truth" version, allow volumes to be booked in advance, operate in real time, and be transparent. The first four properties are self-explanatory and the group agreed with the proposer with little discussion. However, the last three properties all led to some amount of discussion that was much broader than requirements for a public portal tool but that will determine how and why the public would use any tool provided. Privacy and data security were the topics of some of the core discussion, (but are not direct properties of the tool and are discussed separately below).

\section{A. Advanced Booking of Operations}

The prototype UTM system operates in real time, showing the current status of operations that are in the system. Participants listed a desire for both planning and analysis capabilities (forward and backward-looking functions), where the tool can present proposed future UAS activity, and where it can provide data about operations that have been completed. Arguments for these capabilities reflected participants seeing the potential to use a public portal in many ways that extend the use of UTM, for example, to be able to see the amount of UAS activity over an area at some point in the future, to allow for event planning, or being able to assess the density of UAS activity at a specified point in the past. As part of their work activities, participants commented on the usefulness of being able to see proposed UAS operations, and proposed TFRs (temporary flight restrictions) well in advance, as knowing what is planned would assist them in planning their own UAS operations. These future/past capabilities are beyond the scope of the prototype public portal tool defined in the current work, but should be considered for future development.

\section{B. Operate in Real Time}

As noted, the prototype UTM system operates in real time, with the SD tool displaying operation state changes, messages and telemetry, etc., as they occur. The focus groups debated whether members of the public need to see information in real time (first responders do). By contrast, delaying broader data access or visibility might be one way to protect information, e.g., making package delivery times less clear and possibly protecting the UAS operation. If so, what number of minutes of delay of data would be acceptable. There is a precedent set already, through flight following applications accessible by the public [9], which allow the public to track commercial airline flights and which have a delay built in. Typically, the delay is 30 seconds, although U.S. government regulations mean that some U.S. flight data are delayed for five minutes. However, participants were in favor of a delay in the display of data, as they thought it would make little difference to the information the public gleaned and could potentially protect their own information.

\section{Transparency}

Some discussion was devoted to concerns that the UTM system could be misused by operators with bad intentions, using UAS to invade privacy and possibly spy on the public. Participants from occupations that interact with the public said their experience suggests that openness is the best way to combat these concerns. They suggested not only that information should be available about UAS operations but also that efforts should be made to provide educational material about how UTM works, and what data is being passed through the system.

A specific point of the transparency discussion was the detail in which a public portal should describe the payload of the UAS. While some participants thought the payload description should be at a high level only (e.g., "package," "camera") others felt the tool should provide more detail, including if the UAS had any camera capabilities, whether these are recording, and the fidelity with which objects are defined.

\section{Personal Privacy and Data Security}

Although privacy and data security in the UTM system are not direct properties of a public portal tool, these topics were by far the greatest concerns that our focus groups had, and by far the most often and longest discussed. These properties apply to both UAS operators and to the public. Some participants thought USS (UAS Service Supplier) providers and UAS operators need to limit the data that they collect from and with UASs to protect the privacy of the public, while others focused on how much or how little data UAS operators should have to share about their activities with the public through a portal. Groups acknowledged that there are many factors and perspectives in the debate, ranging from maintaining competitive advantage to personal security. For a public portal interface, it is clear that there needs to be a balance struck between full-disclosure and no provided information, but what the optimum point should be was not determined.

\section{Developing a Public Portal}

Using the discussions from the focus groups described above as a guide, the Situation Display (SD) tool was modified to create a first prototype of a NASA Public Information Portal (PIP). The previous design of a dual presentation format for the 
SD was retained, focusing on the properties of simplicity and ease of use. The first step for building the PIP was to reduce the tabular information available to two tables - the operations table and a new flight restrictions table (e.g., Figure 3), deleting the messages table and the UAS certifications tables. The flight restrictions/ TFR table in the PIP identifies the purpose of the TFR and how long it will be in place. TFR position and size are shown on the map in red. The operations table houses similar information to the SD, still: the nature of a flight, its status and

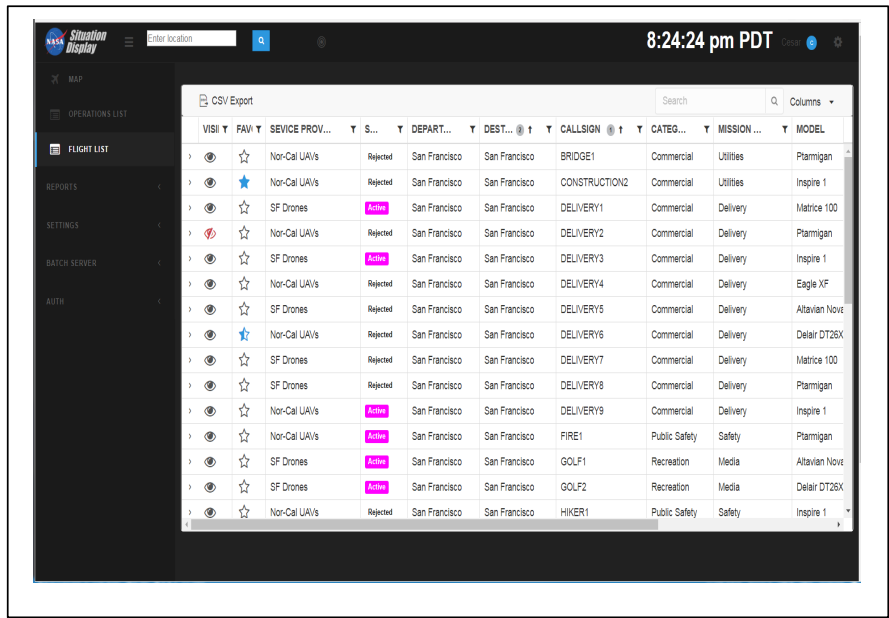

Fig. 3. Public Information Portal tabular display example, showing the new flight list with status and missions

the USS providing the information. Operations information about the operator and certifications were reduced or removed and replaced with more information about flight location and vehicle mission. The scrollbar feature and filter/ sort functions were retained and a filter feature that filters vehicles on the map from actions via the table was added. Each table page shows approximately 40 flights when displayed on two 26 inch monitors.

More alterations and additions were made to the SD map display (Figure 4). The PIP map display offers both satellite and road map views on which operations and aircraft telemetry, that are known to the UTM system, are represented. The color of the operations indicates the state of that operation while the color of the vehicles indicates the type of mission. Aircraft shown on the map have optional data blocks that contain limited flight information which, in the public portal, contain mission information and flight parameters. The map view continues to open around your "home" location but can be dragged to the area of interest. A settings panel on the right can be used to change the size of icons or the data blocks, and show or hide operational volumes.

An informal usability study is being designed to gauge three aspects of a PIP tool: the user-friendliness of the PIP graphical user interface (GUI); an effort to both confirm some of the functions and information focus group participants stated they

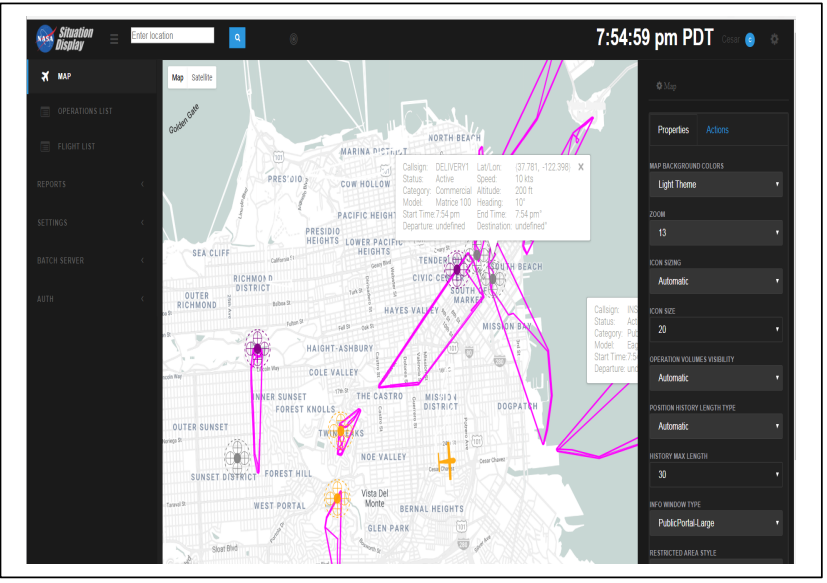

Fig. 4. Public Information Portal map display with operation volumes and vehicle positions on a "light map" background

wanted to see in a tool; and, to collect more data about topics that were not agreed upon in the focus groups, e.g., detail of payload description. To explore some of the points raised above, data that may not be available in future versions of the PIP are present in this first prototype. In addition to inviting a group of participants who have no experience with UTM to test the tool, focus group participants have been invited to return. Participants will be asked to use the PIP to complete a number of tasks similar to those set by other partner sites who have run similar studies (see above). Tasks will be simple walk-up-anduse items including finding vehicles, and identifying their type or mission. During the session, participants will be asked to provide feedback on their experience using the public information portal to complete the tasks, their general opinions on the usability of the portal, and whether there are other functionalities that are desirable.

\section{COMPLEMENTARY SUPPORTING STUDIES}

Preliminary results have been received from the four industry partners who, in parallel to the above work, developed prototype public portals from their original USS designs as part of the recent UTM flight testing. The partners created their public portals using similar approaches to that described in section VI above, and then asked potential user-participants to complete a number of candidate tasks to test the usability of their portals. In total, six additional public portal designs were built. All are slightly different, but all are based around some type of map display and show active UAS operations in the airspace. They report a similar set of user preferences and comments, for example, that the interface needs to be easy to use and quick to respond, and that users want to know "who, what and why," although portals differ somewhat in how much or how little information is made available to public users. Discussion items also fell along similar lines, with partner-users having concerns about privacy, security and preventing a portal being misused by bad actors. 


\section{SUMMARY}

Focus group discussions were an expedient way to gather potential users' ideas for the information in, functions of, and properties of a UTM public information portal. Over thirty people, from a variety of occupations, attended demonstrations of the UTM system and participated in discussions about their desires and concerns regarding having a window into the world of UAS operations available to them. The inception of the public portal work was to provide information to the public while not overstepping the bounds of commercial sensitivity to operators. Participants discussed over 50 items of information, functions and properties that they would like a public portal tool to have. They also outlined a number of key properties including presentation of data in real time and planning views that fed into their chief concerns of personal privacy and data security. In general, discussion supported the findings of [1] with regards to both public concerns and suggestions for addressing these. Participants supported the suggestion that transparency of UTM activity will heavily influence public acceptance, and agreed a public portal will provide much of that transparency through ease of access to information about UAS operations - mainly why and where such operations are taking place. However, participants suggested this has to go further, and some participants advocated for transparency about data flows and data collection as a way to allay the public's fears. Based on the information gathered in the focus groups, a prototype public information portal has been constructed and is being tested using the information gathered from these discussions as a basis for the usability study enquiry.

Various approaches to the display of information and user interfaces are being explored through the development of six additional "flavors" of public portal design by UTM industry partners across different test sites. A small group of userparticipants in each of the five locations were asked to use one of the prototype public portals to complete a number of tasks in a activities that mirrored the phase 2 effort underway at NASA. Preliminary results support the findings from the focus group discussions.

An important aspect of this research is the opportunity it provides to begin to understand the different perspectives of stakeholders of the UTM system and envisioned environment. These perspectives relate to the eventual balance that will need to be struck between providing transparency to the public and supporting the privacy of the operators and information suppliers.

\section{ACKNOWLEDGMENT}

We are grateful to all our focus group participants, who attended our discussions and gave such insightful and thoughtful comments.

\section{REFERENCES}

[1] UTM RTT working group, "Unmanned Aircraft System (UAS) Traffic Management (UTM)," NextGen Concept of Operations V1.0, FAA, Washington, DC, 2018.

[2] Bracken-Roche, C., Lyon, D., Mansour, M., Molnar, A., Saulnier, A., and Thompson, S., "Surveillance drones: Privacy implications of the spread of Unmanned Aerial Vehicles (UAVs) in Canada," Kingston, ON, Canada: Surveillance Studies Centre, Queen's University, 2014.

[3] Clothier, R., Greer, D., Greer, D., \& Mehta, "Risk perception and the public acceptabce of drones," Risk Analysis, 35 (6), 1167$1183,2015$. [4] FAA, "FAA UAS data on a $\mathrm{ml}$ ? id=9c2e4406710048e19806ebf6a06754ad, Washington, D.C., 2018

[5] Johnson, M., Jung, J., Rios, J., Mercer, J., Homola, J., Prevot, T., Mulfinger, D., and Kopardekar, P., "Flight test evaluation of an Unmanned Aircraft System Traffic Management (UTM) Concept for multiple beyond visual line of sight operations," Twelfth USA/Europe Air Traffic Managements Research and Development Seminar (ATM 2017), Seattle, WA, June 26-30, 2017.

[6] Homola, J., Dao, Q., Martin, L., Mercer, J., Mohlenbrink, C., \& Claudatos, L., "Technical Capability Level 2 Unmanned Aircraft System Traffic Management (UTM) Flight Demonstration: Description and Analysis," $36^{\text {th }}$ Digital Avionics Systems Conference (DASC2017), Orlando, FL, 2017.

[7] Perez, S., "Google Earth and Maps get sharper satellite imagery with new update," Oath Tech Network, techcrunch.com, 2016.

[8] Gibbs, G., "Thematic coding and categorizing. Analyzing qualitative data," London, Sage Publications, 2007.

[9] FlightAware, "FlightAware: Live flgiht tracking," https://flightaware.com, Houston, TX, 2018. 